\title{
Spatial mobility and social outcomes
}

\author{
William A. V. Clark • Maarten van Ham • Rory Coulter
}

Received: 28 January 2013/ Accepted: 27 October 2013/Published online: 12 November 2013

(C) Springer Science+Business Media Dordrecht 2013

\begin{abstract}
This paper examines the nature and extent of socio-spatial mobility in Great Britain. In contrast with previous studies, we investigate the entire spectrum of moves within and across the hierarchical structure of neighbourhoods. We use data from the British Household Panel Survey to trace moves between neighbourhoods defined using the Indices of Multiple Deprivation. We define upward socio-spatial mobility as moving to neighbourhoods with greater levels of advantage (lower levels of deprivation), and downward socio-spatial mobility as the shift to less advantaged neighbourhoods. As expected, the results show that there are strong associations between origin and destination neighbourhood types. We find that education and income play critical roles in the ability of individuals to make neighbourhood gains when they move. An important finding of the research is the way in which the housing market structurally conditions socio-spatial mobility. In the UK and probably more broadly, the opportunity to move to socially advantaged places is highly stratified by housing tenure.
\end{abstract}

Disclaimers: The BHPS data used in this study were made available through the ESRC Data Archive. The data were originally collected by the ESRC Research Centre on Micro-Social Change at the University of Essex (now incorporated within the Institute for Social and Economic Research). Neither the original collectors of the data nor the Archive bear any responsibility for the analyses or interpretations presented here. Census output is Crown copyright and is reproduced with the permission of the Controller of HMSO and the Queen's Printer for Scotland.

W. A. V. Clark

Department of Geography, University of California at Los Angeles, Los Angeles, CA 90095-1524,

USA

e-mail: wclark@geog.ucla.edu

M. van Ham ( $\square)$

OTB, Research for the Built Environment, Faculty of Architecture and the Built Environment, Delft University of Technology, P.O. Box 5030, 2600 GA Delft, The Netherlands

e-mail: m.vanham@tudelft.nl

R. Coulter

Department of Sociology, University of Cambridge, Free School Lane, Cambridge CB2 3RQ, UK

e-mail: rcc46@cam.ac.uk 
Keywords Residential mobility · Residential sorting · Socio-economic status ·

Deprivation $\cdot$ Neighbourhoods

\section{Introduction}

The neighbourhoods we live into a large extent reflect our socio-economic position in society, as our purchasing power determines the types of places we can access (Cheshire 2011). As such, possessing the ability to move and especially the ability to leave less advantaged neighbourhoods is central for achieving the social gains and access to opportunities provided by more advantaged locations. Moving to a more advantaged neighbourhood is often also an escape from the problems that are concentrated in less advantaged places. As a result, it is often argued that residential mobility and migration are key mechanisms for effecting social mobility. This is of great relevance in the United Kingdom (UK), as the 2011 Strategy for Social Mobility suggests that greater social fluidity benefits society as a whole by producing gains in both productivity and subjective well-being (Cabinet Office 2011).

While there is a large literature examining social mobility in terms of income, social class and employment status (Goldthorpe and Llewellyn 1987; Breen 2004) less is known about the mobility of people between different types of neighbourhoods. There is a large literature examining moves into and out of the most disadvantaged neighbourhoods (Bailey and Livingston 2008), but there is still much to learn about mobility patterns across the entire neighbourhood hierarchy. In particular, we need to know more about those who make lateral moves between similar types of neighbourhood (thereby making limited gains in neighbourhood status or quality), as well as those who move up and make the social gains we often associate with the notion that we 'move to improve'. As a result, our analysis seeks to improve our understanding of residential mobility in the context of local places and their characteristics by measuring the odds of people changing their position within the whole socio-spatial system. Because the spatial and social are so clearly intertwined we invoke the notion of movement across spatial scales, which by definition brings social change. As a significant addition to previous work we ask how much mobility there is for mid-level households. Are these households able to affect upward social mobility with residential change, or is it only the affluent that can move and move up, so that other households are marginalized and left to "pick up the pieces"? Their mobility as well as their location may therefore be residualized within the larger urban mosaic.

As residential mobility is the engine of change in the city, exploring who gains and loses through (im)mobility will enrich our understanding of how individuals effect social mobility. Thus, our study asks which individuals and households can adjust their housing and neighbourhood circumstances by moving and whether such geographic adjustments increase or decrease their socio-spatial mobility. Answering this question on geographic adjustments is important for understanding the recursive relationships between individual moving behaviour and the changing geography of socio-economically stratified neighbourhoods. As most people only move very short distances when they relocate, we expect that most people move within very similar types of neighbourhoods (Bailey and Livingston 2007). Still, we know that some households are able to make quite large changes in their neighbourhood contexts and it is these 'off-diagonal' moves which are also important in understanding spatial outcomes and upward and downward mobility. We also investigate the specific role of the urban structure, notably housing tenures, in facilitating or negating mobility opportunities. 
Specifically, our paper seeks to answer three questions-(1) how localized are moves across the socio-spatial structure? (2) what are the predictors of movement across the socio-spatial structure? and (3) to what extent can people move up the socio-spatial ladder given their neighbourhood of origin? The long term run of the British Household Panel Survey (BHPS) provides the research data base to realistically evaluate the influence of residential on socio-spatial change in the UK. Using a longitudinal resource such as the BHPS also enables us to analyse socio-spatial stability, as we can identify individuals who are immobile over long periods of time.

\section{Previous research}

The long history of mobility research beginning with the work of Park, Burgess and the Chicago school has been infused by the notion that we move to improve. This perspective emphasizes that people make a series of moves over the life course in order to bring their housing needs and employment opportunities into equilibrium and hence attain higher levels of satisfaction (Clark and Dieleman 1996; Martin and Lichter 1983). This interest in the individual dimension of social change has been paralleled by a concern for the role of place in structuring social mobility (van Ham and Manley 2010; van Ham et al. 2012), particularly on the part of governments who have sought to create "communities of opportunity" - places with good schools, access to jobs, quality housing choices, safe streets, services and strong social networks. As residential mobility provides the mechanism linking the social mobility of individuals to the changing composition of neighbourhoods, understanding how places influence and are simultaneously influenced by mobility requires an integrated place and household based approach (Bailey and Livingston 2008). This has been a frequent theme in recent policy programs, which often aim to integrate disparate approaches to social inequality and deprivation (Manley et al. 2013).

Understanding the spatial structure of metropolitan areas and also the geography of residential mobility requires consideration of both housing prices and ethnicity. Over time, differences in preferences and purchasing power have created a residential mosaic that is stratified by both class and race (Friedman 2011; South et al. 2005). It is within this mosaic that the choices of households are made, in turn reinforcing or reconstructing the mosaic as the choices are executed. Residential mobility outcomes are not random, but are influenced by the ability of individuals to 'reveal' their preferences to live near to similar households (for instance in terms of income, composition and ethnicity). The aggregate outcome of the execution of constrained choices is sorting, resulting in the grouping (segregation) of similar individuals into spatially defined areas (neighbourhoods) from which we often observe common outcomes. For example, the fact that Toronto's neighbourhoods have become more polarized by income over the last few decades could reflect the increasing attention assumed neighbourhood effects have received by those with the ability to choose (Hulchanski 2007). It seems likely that the greater the resources available to households, the greater their ability to discriminate among possible places to live. In time, this selective mobility will increase the polarization of neighbourhoods, which will in turn influence residential mobility patterns. This underlines the way in which selective migration processes can erode any gains made by place-based responses to concentrated disadvantage (Bailey and Livingston 2008).

At the same time, societies often strive to limit the uneven distribution of household income for both equity and efficiency reasons. However, individuals and their families are highly spatially correlated in both socio-economic and educational terms. Where housing is 
allocated primarily through the market, families group spatially and will likely generate distributional inequality (Worner 2006; Cheshire 2011). This could have implications for the social attainment of residents. If the residential sorting process helps to polarize neighbourhoods, some places will experience a more rapid socio-economic descent than others. This descent process may in turn initiate threshold effects on the social behaviour of residents (Meen 2006; Meen et al. 2012). In this sense, neighbourhoods can have the potential to generate effects (both positive and negative) which result directly from residential sorting, as extensive reviews of the literature have shown (Dietz 2002; Durlauf 2004; Friedrichs et al. 2003; van Ham et al. 2012).

Life course theories suggest that understanding the links between individual moving behaviour and the spatial patterning of neighbourhoods requires considering how macrocontextual factors influence residential mobility (Mulder and Hooimeijer 1999). This can occur when housing is allocated bureaucratically, as it is in the British social (public) housing sector. ${ }^{1}$ Thus, as access to social housing is typically restricted to the most economically marginal households and stock is often concentrated in the least desirable places (Burrows 1999), the social housing system can channel the most disadvantaged people into the least advantaged places. Whether, and to what extent, this spatial organization of income inequality affects socio-spatial mobility processes will emerge as a major contribution from the empirical analysis in our paper. While we expect to find significant 'within-neighbourhood' lateral socio-spatial mobility, there may be more adjustment in the full matrix than is typically recognized by studies focusing solely on poor neighbourhoods (Bailey and Livingston 2007).

There is already a substantial literature examining moves out of deprived areas (South and Crowder 1997; South et al. 2005; Quillian 2003), as well as churning and mobility processes across deprived neighbourhoods (Robson et al. 2008). However until recently, much less attention has been directed towards the entire spectrum of neighbourhoods that households enter, reside within and subsequently exit. This is now changing, with new studies of neighbourhood effects devoting increasing attention to processes of neighbourhood sorting (van Ham and Clark 2009; Feijten and van Ham 2009; Hedman et al. 2011). Much of this newer literature does not however focus specifically on the role of mobility, as the emphasis still tends to be on where people live and not where they move to.

Two recent British studies have taken up the issue of residential mobility, tenure and the inter-relationship with neighbourhood contexts (Boheim and Taylor 2002; Rabe and Taylor 2010). These studies specifically address actual moves between neighbourhoods and regions. While the first of these studies is more concerned with the joint housing and job mobility process, Rabe and Taylor (2010) focus on neighbourhoods themselves to show that life course events do not always lead to neighbourhood quality adjustments. Importantly, Rabe and Taylor (2010) separate and analyse both the objective and subjective gains/losses people make moving between neighbourhoods. Our study is related but directed more towards the broad probability of making gains or suffering losses in neighbourhood quality consequent on a move between neighbourhoods. In a break with much previous research, we seek to analyse changes in neighbourhood quality across the full spectrum of neighbourhood types (Bolt et al. 2008; Clark and Rivers 2012). Recently, a New Zealand study of movement across a set of neighbourhoods found that the degree of

\footnotetext{
1 The British housing system is often considered to consist of three basic tenure regimes: homeownership, social rental (housing rented at below market rates from a local authority or housing association) and private rental (housing rented through the market system).
} 
upward mobility achieved is negatively affected by the level of deprivation at the neighbourhood of origin. Even after controlling for the attributes of movers, people moving from more deprived areas were found to have a lower degree of upward mobility than movers from more advantaged places (Clark and Morrison 2011). The current paper extends these studies, focusing in particular on how the housing market conditions the social mobility of movers.

\section{Data preparation}

\subsection{BHPS data}

Given the detailed information collected by the UK census, linking individual census records through time can provide insight into how individuals move through different types of neighbourhood across the life course. Such an approach is, however, constrained by the 10-year intervals separating census observations. This weakness can be overcome by integrating longitudinal data from the British Household Panel Survey (BHPS) with microgeographic information derived from other sources. This approach enables us to test hypotheses linking the changing attributes and composition of households to the changes in neighbourhood outcomes which can occur with spatial mobility.

This study draws on the original BHPS sample of 10,300 individuals interviewed in 1991 and tracked and re-interviewed each subsequent year until 2008 (Taylor et al. 2010). The sample also includes individuals from approximately 3,000 'booster' Scottish and Welsh households tracked from 1999 to 2008. After transforming the dataset into personyear format, one individual from each original and booster household was randomly selected in 1991 and 1999 respectively. ${ }^{2}$ These individuals were then tracked across all waves of the survey. Young adults living with their parents were not eligible for selection, as they have not been responsible for choosing their initial residential location. Following random selection, we are left with 8,421 individuals providing a nominal total of 102,331 person-year observations. This pool of person-years was used to derive the sample for each of our analyses. While attrition rates in the BHPS are comparatively low (Buck 2000), the long duration of our study does mean that many of these cases are unusable due to participant dropout and occasional non-response. This could be problematic if attrition is selective, although results reported by Rabe and Taylor (2010) indicate that attrition has fairly minimal effects upon wave-to-wave analyses of mobility using the BHPS.

\subsection{Indices of multiple deprivation}

Micro-geographic information on the location of residence was then merged onto each person-year record to identify where each person was living each year. Given the devolved nature of UK administration, the available micro-geographic units differ between England/ Wales and Scotland. Lower Super Output Areas (LSOAs) were available for individuals in England and Wales, while the datazone (DZ) of residence was merged onto records from

\footnotetext{
2 This procedure ensures that only one person per household is included in our analyses. Including multiple members from the same household would bias our results against the relocation decisions of smaller households. Of course, we cannot know how significantly the selected household member influenced relocation decisions. This may be problematic in the case of 'tied movers', whose moving behaviour is strongly influenced by the needs of their partner (Cooke 2008).
} 
individuals in Scotland. Both LSOAs and DZs are constructed at a very fine scale. LSOAs contain an average of 1,500 people, while the average population of a Scottish datazone is 750 (ONS 2010). Although often overlooked in studies of neighbourhood change, it is important to remain aware that how neighbourhoods are defined can affect the results. ${ }^{3}$ Our focus on very fine scale micro-geographies helps minimize these issues.

Measures capturing the level of LSOA/DZ 'advantage' were then merged onto the BHPS dataset. Here we draw upon the Indices of Multiple Deprivation (IMD) produced for each devolved administration; IMD 2004 for England, SIMD 2004 for Scotland and WIMD 2005 for Wales. Each index is computed using information about the LSOA/DZ across multiple domains of 'deprivation' (see Noble et al. 2004; Scottish Executive 2004; Welsh Government 2005 for full details). The raw data for each indicator come from a variety of administrative or census sources (Noble et al. 2004; Scottish Executive 2004; Welsh Government 2005). After each LSOA/DZ has been allocated a score in each domain, the domain scores are transformed, combined and weighted to give overall LSOA/DZ score and rank values. Less advantaged LSOA/DZs are allocated higher IMD scores. An important assumption with our use of the IMD measures is that deprivation values calculated in 2004-2005 are appropriate for the entire study period (1991-2008). This may not be the case if neighbourhood attributes change rapidly, although existing evidence suggests that relative levels of neighbourhood quality remain quite static over time (Meen et al. 2007, 2012). The problem of changing neighbourhood attributes is also minimized by the indicators used to compute the IMD measures. In many cases, the raw data used to calculate the domain scores were gathered several years before the publication of each index. ${ }^{4}$

In addition to calculating a score for each LSOA/DZ, LSOA/DZs are also ranked based upon their relative level of neighbourhood quality. These rank values can be grouped into deciles. In this study, decile 1 contains the most advantaged $10 \%$ of LSOA/DZs within each country, while decile 10 contains the least advantaged $10 \%$. The distribution of scores by decile for each country is presented in Table 1, while the distribution of English IMD scores by decile is depicted graphically in Fig. 1 (the Scottish and Welsh equivalents are highly similar). Figure 1 shows that the less advantaged the decile, the larger the range of neighbourhood scores within it. This is partly due to the methodology used to construct the IMD indices (which are specifically designed to identify small pockets of deprivation), but it also reflects the huge variation in neighbourhood quality within the least advantaged decile. It is important to be aware that the construction of the IMD measures varies between countries (ONS 2010). ${ }^{5}$ Although this means that the raw scores are not directly comparable over national boundaries, Table 1 shows that the distribution of scores by decile does not actually differ substantially across countries. Hence, we feel it is justifiable to pool observations from across the three countries when analysing how individuals move between different types of neighbourhood.

Each time an individual was observed to have moved between two consecutive waves of the BHPS, we computed a change score variable by comparing the IMD scores of the origin and destination LSOA/DZ. Positive changes in score indicate moves to less

\footnotetext{
3 This is often termed the Modifiable Areal Unit Problem/Phenomenon (MAUP) (Manley 2006).

${ }^{4}$ Census derived indices of socio-economic (dis)advantage (Townsend and Carstairs scores) were also considered. These indices consist of deprivation scores produced for geographic units using four census variables about the socio-economic composition of the area. However, the multidimensional nature of socioeconomic (dis)advantage captured by the IMD indicators made these more attractive for this study.

5 This may constitute a further advantage over census based indices, as it enables us to more effectively capture geographical differences in the nature of socio-economic (dis)advantage.
} 
Table 1 The distribution of English, Scottish and Welsh IMD scores by IMD decile

\begin{tabular}{|c|c|c|c|c|c|c|c|c|c|}
\hline \multirow[t]{2}{*}{ Decile } & \multicolumn{3}{|c|}{ English IMD 2004 scores } & \multicolumn{3}{|c|}{ Scottish SIMD 2004 scores } & \multicolumn{3}{|c|}{ Welsh WIMD 2005 scores } \\
\hline & Mean & Min & $\operatorname{Max}$ & Mean & Min & $\operatorname{Max}$ & Mean & Min & $\operatorname{Max}$ \\
\hline 1 & 4.07 & 0.61 & 5.74 & 3.87 & 1.03 & 5.37 & 4.69 & 1.40 & 6.90 \\
\hline 2 & 7.03 & 5.75 & 8.34 & 6.66 & 5.38 & 7.72 & 8.37 & 7.00 & 9.90 \\
\hline 3 & 9.62 & 8.35 & 10.96 & 8.96 & 7.75 & 10.49 & 11.13 & 10.00 & 12.40 \\
\hline 4 & 12.29 & 10.96 & 13.71 & 11.85 & 10.55 & 13.49 & 13.71 & 12.40 & 14.90 \\
\hline 5 & 15.36 & 13.72 & 17.02 & 15.19 & 13.54 & 16.94 & 16.30 & 14.90 & 17.90 \\
\hline 6 & 18.94 & 17.02 & 21.15 & 18.94 & 16.96 & 21.02 & 19.45 & 17.90 & 21.20 \\
\hline 7 & 23.71 & 21.16 & 26.61 & 23.32 & 21.07 & 26.11 & 23.88 & 21.30 & 26.20 \\
\hline 8 & 30.14 & 26.61 & 34.20 & 29.80 & 26.17 & 33.48 & 29.08 & 26.40 & 32.60 \\
\hline 9 & 39.01 & 34.21 & 45.19 & 39.04 & 33.58 & 45.43 & 37.53 & 32.80 & 41.90 \\
\hline 10 & 56.36 & 45.26 & 85.59 & 57.99 & 45.53 & 87.09 & 52.85 & 42.50 & 78.90 \\
\hline Total & 21.27 & 0.61 & 85.59 & 20.71 & 1.03 & 87.09 & 21.84 & 1.40 & 78.90 \\
\hline
\end{tabular}

Source: BHPS with merged IMD data

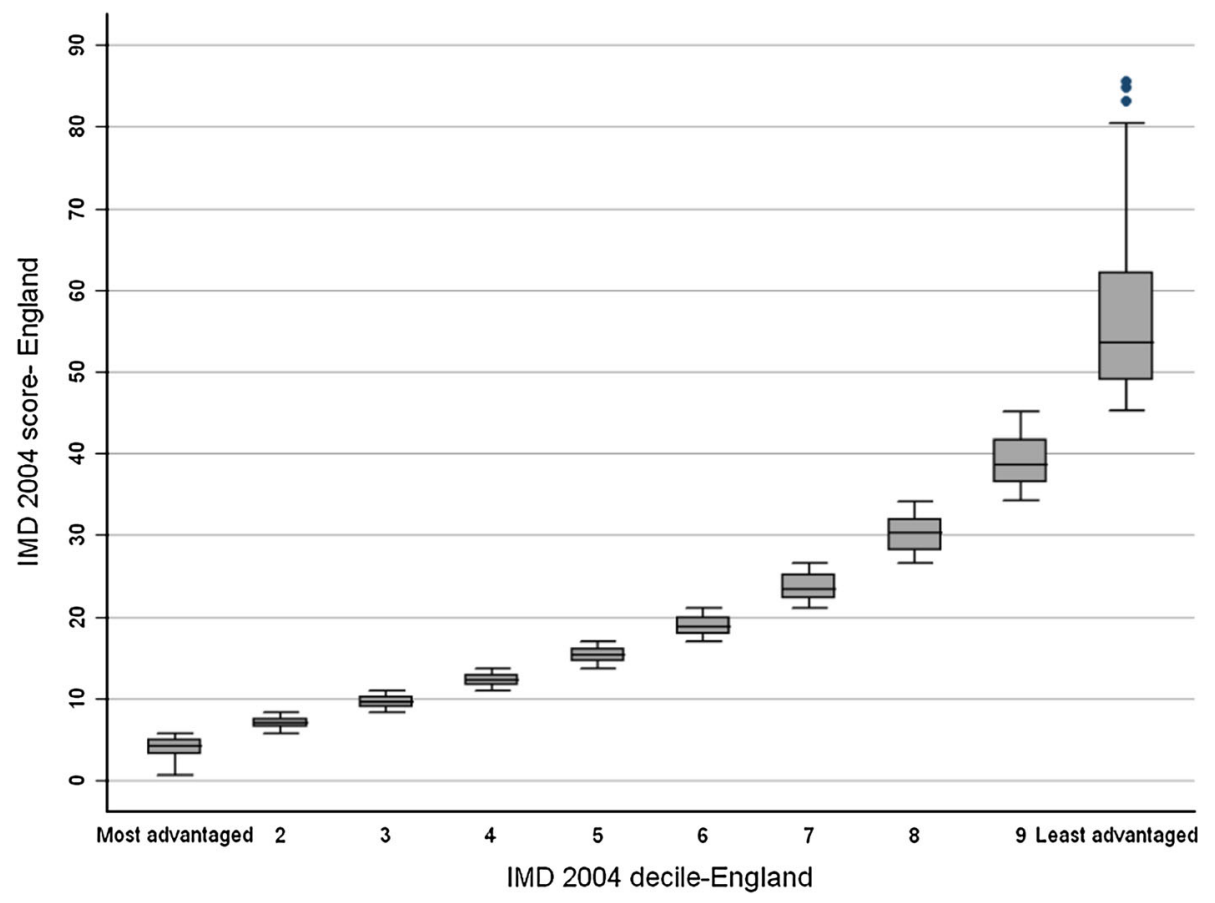

Fig. 1 Box plot of English LSOA IMD 2004 scores by decile

advantaged neighbourhoods, while decreases in scores denote moves to more advantaged neighbourhoods. We also observed whether moving individuals changed their neighbourhood decile. To provide some additional contextual information about the effects of changing neighbourhood decile, Table 2 provides summary statistics (derived from the 2001 Census) about the ethnic, socio-economic and tenure composition of the different 
Table 2 Mean attributes of LSOAs/DZs in each deprivation decile by country

\begin{tabular}{|c|c|c|c|c|c|c|c|c|c|c|}
\hline \multirow[t]{3}{*}{ Country } & \multicolumn{10}{|c|}{ Mean composition of LSOA/DZ population in 2001} \\
\hline & \multicolumn{8}{|c|}{ Most advantaged } & \multicolumn{2}{|c|}{ Least advantaged } \\
\hline & 1 & 2 & 3 & 4 & 5 & 6 & 7 & 8 & 9 & 10 \\
\hline \multicolumn{11}{|c|}{$\%$ non-white ethnic minority } \\
\hline England & 3.26 & 3.20 & 3.94 & 3.71 & 4.16 & 6.42 & 7.06 & 10.55 & 12.04 & 15.35 \\
\hline Wales & 2.67 & 1.31 & 1.31 & 1.11 & 1.31 & 1.15 & 1.34 & 1.30 & 1.06 & 1.21 \\
\hline Scotland & 2.62 & 2.35 & 2.18 & 1.49 & 1.88 & 2.17 & 2.08 & 1.80 & 1.67 & 1.75 \\
\hline \multicolumn{11}{|c|}{$\%$ unemployed } \\
\hline England & 2.12 & 2.47 & 2.81 & 3.04 & 3.83 & 4.48 & 5.34 & 6.87 & 8.80 & 13.12 \\
\hline Wales & 2.85 & 3.79 & 4.39 & 4.51 & 5.12 & 6.03 & 6.64 & 6.97 & 8.51 & 11.70 \\
\hline Scotland & 2.31 & 2.97 & 3.16 & 3.87 & 4.76 & 5.59 & 6.96 & 8.49 & 11.86 & 15.79 \\
\hline \multicolumn{11}{|c|}{$\%$ social renting households } \\
\hline England & 3.72 & 6.01 & 8.13 & 9.83 & 11.20 & 15.03 & 18.59 & 27.23 & 36.01 & 46.90 \\
\hline Wales & 2.62 & 7.44 & 10.77 & 11.39 & 13.24 & 16.13 & 19.13 & 24.54 & 27.94 & 44.54 \\
\hline Scotland & 2.19 & 5.99 & 10.99 & 17.01 & 23.25 & 26.50 & 37.45 & 44.60 & 51.07 & 66.95 \\
\hline \multicolumn{11}{|c|}{$\%$ private renting households } \\
\hline England & 5.68 & 6.60 & 7.30 & 8.23 & 8.50 & 9.85 & 10.27 & 12.17 & 11.38 & 11.42 \\
\hline Wales & 4.84 & 8.60 & 9.36 & 9.03 & 8.85 & 8.57 & 11.23 & 8.04 & 7.83 & 5.65 \\
\hline Scotland & 6.31 & 7.38 & 9.15 & 11.84 & 10.65 & 9.50 & 7.73 & 7.67 & 7.41 & 3.99 \\
\hline
\end{tabular}

Source: 2001 Census: Census Area Statistics (England and Wales). Data for Scottish datazones derived from the 2001 Census and supplied by the General Register Office for Scotland (Scotland). C C Crown Copyright

neighbourhood deciles in each of the devolved administrations. The table shows that in England, the least advantaged deciles have large proportions of non-white ethnic groups. Scotland and Wales have much lower proportions of ethnic minorities and these are more evenly distributed across the neighbourhood hierarchy. Across all three countries, the unemployment rate rises as the level of neighbourhood disadvantage increases. The least advantaged deciles in all three countries are also characterized by concentrations of social housing, although the relationship between private renting and neighbourhood (dis)advantage is more varied and ambiguous.

\section{Research findings}

\subsection{Matrices of movement and stability}

Initial analyses reveal that an average of $10.8 \%$ of BHPS participants changed address in each year of the survey (Buck 2000; Boheim and Taylor 2002). This closely matches estimates of British mobility rates derived from both the 2001 Census and Labour Force Survey data (Dixon 2003: 192; Bailey and Livingston 2007: 14). Bailey and Livingston's (2007) analyses of 2001 Census data show that this mobility rate varies somewhat across deprivation deciles, ranging from a rate of about $11.5 \%$ in the least advantaged deciles to $8.0 \%$ in the most advantaged deciles. Importantly, Bailey and Livingston's work demonstrates that these differences in turnover rates are primarily driven by the population 
composition of the different neighbourhood deciles, rather than the characteristics of the deciles themselves.

With this contextual background in mind, we begin by investigating the pattern of movement by origin and destination neighbourhood for all move events in our sample. These patterns confirm that the majority of moves are made 'laterally' between similar types of neighbourhood (Table 3). In addition, the proportion of transitions decreases as the difference in deprivation between the origin and destination neighbourhoods grows. The concentration in the decile of origin varies from around $40 \%$ for the least advantaged neighbourhoods, to somewhat more than a third for the most advantaged areas. Overall, slightly more than one quarter of all movers stayed within the neighbourhood of origin, while the middle level neighbourhoods had much lower levels of retention than either extreme. Clearly, it is within the middle range of neighbourhoods that much of the neighbourhood change is occurring.

Overall, $51.4 \%$ of all moves were either within the neighbourhood of origin or to a neighbourhood within an adjacent decile. Large changes in neighbourhood quality with a move are quite rare. This may be because most households have limited financial resources and cannot buy into significantly better neighbourhoods. In addition, neighbourhood (dis)advantage is spatially concentrated and most moves occur over short distances. Nonetheless, we can see from the matrix that there is considerable movement in the offdiagonal cells. These moves will be the focus of our subsequent analyses.

The matrix highlights what will be a central point in our discussion, that movers from different origin neighbourhoods do not distribute themselves randomly across available destinations. On the contrary, the table illustrates the systematic relationship between origin and destination deciles. At the same time the probabilities of movement shows that overall, there is a significant likelihood of moving to a more advantaged neighbourhood when relocating. Table 3 shows that there is a $41.8 \%$ chance that a move will be made to a more advantaged neighbourhood, in comparison to a $31.6 \%$ chance that a move will lead to a poorer neighbourhood. In the context of "we move to improve", the data demonstrate that individuals who move typically make status gains. The table emphasizes that over our period of study there is considerable re-adjustment as households make their housing and social moves in tandem.

While the table shows some socio-spatial fluidity, there is also considerable social and spatial stability beyond that visible in Table 3 . We could call it the background structure in which moves occur but they do not "break out" of their local areas. For complete (18 year) records and excluding the booster sample members, further analysis showed that on average individuals live about 8-12 years in the decile in which they were observed in 1991. A not insignificant number of people have been in the same decile for most of their residential careers. This suggests that while mobility has been the major concern of studies of social change, immobility should be given much more attention if we are to better understand how much social change occurs in a given society (Cooke 2011; Coulter and van Ham 2013). People who move locally, but do not change neighbourhood type, and those who do not move at all, are together a measure of the lack of dynamism in the system.

\subsection{Understanding changes in neighbourhood types}

The previous section focused on the movements of all individuals between different types of neighbourhoods. In this section we unpack these aggregate changes to investigate how three important factors - age, income and housing tenure - are linked to the neighbourhood outcomes of moves. In the following discussion, it is important to keep in mind that there are 


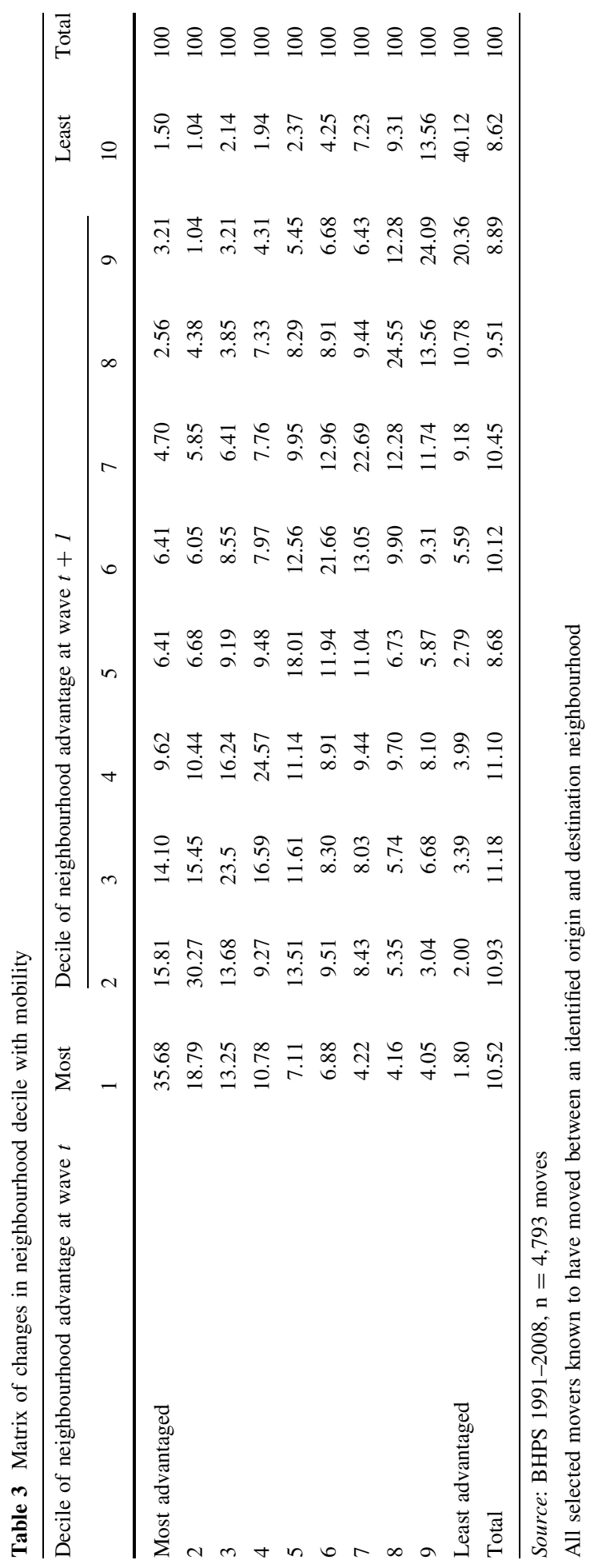


structural constraints in the movement across neighbourhood types. A household or individual in the most advantaged group of neighbourhoods can only remain where they are or move to neighbourhoods which are less advantaged, and, as a corollary, households or individuals in the least advantaged neighbourhoods can only increase their status or remain where they are. To move beyond the significant tendency to remain in the neighbourhood of origin or a nearby neighbourhood (seen in Table 3), we therefore define changes as spatial movements involving a change in neighbourhood quality of at least two deciles in status.

It has been well established that younger people generally move more frequently than older people (Clark and Dieleman 1996). But although age is strongly linked to the probability of moving, it is less a determinant for the probability of moving up or down in status, as the differences across age are muted (Table 4a, b). Above the middle deciles, there is a slightly higher probability of younger individuals moving up and this is also true for older individuals in the middle ranges of the advantage scale. Those in deciles 5 and 6 are more likely to move up and less likely to move down. Clearly, their life course trajectory is still one of upward mobility in the housing market. Although the cell sizes in Table $4 \mathrm{a}, \mathrm{b}$ are rather small, Table $4 \mathrm{a}$ and $\mathrm{b}$ still provide powerful evidence of considerable fluidity in the overall matrix. It seems unlikely that larger samples would alter these basic results.

While age has a rather muted impact, household income is closely associated with the neighbourhood outcomes of residential moves (Table 5a, b). Individuals in the lowest quartile of real household incomes are significantly more likely to move to less advantaged areas. In contrast, higher incomes provide the opportunity for people to move up or maintain residence in more advantaged places. Very few households in the top income quartile move to very disadvantaged neighbourhoods. This finding reiterates the structural difficulty for lower income households to make more than marginal gains in neighbourhood quality when they move, demonstrating that selective mobility flows help to produce stratified neighbourhoods.

Tenure and income are related and the outcomes across tenure reinforce the effect of socio-economic status on residential relocations (Table 6a, b). Again the extremes have relatively small samples (e.g. very few social renters live and move within the most advantaged deciles), but the overall pattern is clear. Homeowners are more often able to move out of less advantaged areas and social renters are likely to move out of the most advantaged areas and down the neighbourhood hierarchy. It appears that social renters, even if they live initially in more advantaged neighbourhoods, are unable to maintain their status in such neighbourhoods when they move. This could be due to the relative concentration of socially rented properties in less desirable locations (Table 2). In addition, social renters moving into private rental housing are likely to only be able to afford properties with low rents in the least desirable locations. Again, our findings reiterate that the housing market conditions and structures household mobility behaviour, reproducing the socio-economic segmentation of neighbourhoods.

\subsection{Changes in neighbourhood scores with residential moves}

Thus far the analysis has focused on the changes in deprivation decile which can occur with mobility. We now turn to investigate changes in the raw LSOA/DZ scores. When an individual moves from one neighbourhood to another there is an associated change in their deprivation score. We can derive this change score value $\left(\Delta \mathrm{S}_{\mathrm{ij}}\right)$ by subtracting the origin neighbourhood score $\left(S_{i}\right)$ from the destination neighbourhood score $\left(S_{j}\right)$ Hence:

$$
\Delta \mathrm{S}_{\mathrm{ij}}=\mathrm{S}_{\mathrm{j}}-\mathrm{S}_{\mathrm{i}}
$$


Table 4 The percentage of moving individuals by age and origin decile who move (a) up and (b) down by at least two deciles

\begin{tabular}{|c|c|c|c|c|c|c|c|c|c|c|c|}
\hline \multirow[t]{2}{*}{ Age } & & \multicolumn{2}{|c|}{ More advantaged } & \multicolumn{6}{|c|}{ Decile } & \multicolumn{2}{|c|}{ Less advantaged } \\
\hline & & 1 & 2 & 3 & 4 & 5 & 6 & 7 & 8 & 9 & 10 \\
\hline \multicolumn{12}{|l|}{ (a) } \\
\hline \multirow[t]{2}{*}{$16-34$} & $\%$ & & & 12.42 & 23.08 & 36.69 & 30.77 & 44.22 & 41.21 & 44.33 & 40.00 \\
\hline & $\mathrm{n}$ & & & 19 & 33 & 51 & 52 & 88 & 82 & 90 & 76 \\
\hline \multirow[t]{2}{*}{$35-54$} & $\%$ & & & 15.79 & 19.39 & 27.75 & 33.33 & 41.44 & 42.94 & 54.55 & 37.78 \\
\hline & $\mathrm{n}$ & & & 30 & 38 & 48 & 64 & 75 & 76 & 96 & 68 \\
\hline \multirow[t]{2}{*}{$55+$} & $\%$ & & & S.S & 17.09 & 35.24 & 38.89 & 36.52 & 40.50 & 47.27 & 42.40 \\
\hline & $\mathrm{n}$ & & & & 20 & 37 & 49 & 42 & 49 & 52 & 53 \\
\hline \multicolumn{12}{|l|}{ (b) } \\
\hline \multirow[t]{2}{*}{$16-34$} & $\%$ & 52.27 & 36.09 & 37.25 & 28.67 & 25.90 & 21.89 & 12.06 & 9.05 & & \\
\hline & $\mathrm{n}$ & 69 & 48 & 57 & 41 & 36 & 37 & 24 & 18 & & \\
\hline \multirow[t]{2}{*}{$35-54$} & $\%$ & 45.09 & 33.48 & 27.89 & 30.61 & 29.48 & 18.75 & 15.47 & 9.60 & & \\
\hline & $\mathrm{n}$ & 101 & 78 & 53 & 60 & 51 & 36 & 28 & 17 & & \\
\hline \multirow[t]{2}{*}{$55+$} & $\%$ & 48.54 & 37.38 & 38.66 & 28.21 & 20.00 & 19.05 & 13.91 & S.S & & \\
\hline & $\mathrm{n}$ & 50 & 40 & 46 & 33 & 21 & 24 & 16 & & & \\
\hline
\end{tabular}

S.S denotes fewer than 15 cases

This change score can be quite modest and in such cases, the household or individual is likely to move within the current decile category. Over all the waves of the BHPS, the changes in deprivation scores range from about -60 to +60 points, with the majority of changes clustered in the range of -10 to +10 . Indeed, approximately half of all moves generate a score change between -8 and +5 . This reinforces our argument that most individuals move between similar types of neighbourhood.

To understand the effect of neighbourhood of origin on subsequent mobility outcomes, we estimate exploratory linear regression models where the change in the IMD score occurring with a move is the dependent variable. In these models, we use the IMD score of the origin neighbourhood as the sole independent variable. We show two regression models containing the score changes for movers from all countries in a scatter plot (Fig. 2). Given that Table $6 \mathrm{a}, \mathrm{b}$ have shown that housing tenure has a particularly strong influence on the neighbourhood changes which occur with mobility, we have estimated separate regression lines for different tenure groups. These are the downward sloping lines on the graphs, with the narrow shading around each line indicating the $95 \%$ confidence intervals of the estimate. There is evidence that these relationships are somewhat nonlinear, so we estimate the lines using the equation:

$$
\Delta \mathrm{S}_{\mathrm{ij}}=\alpha+\beta_{1} \mathrm{~S}_{\mathrm{i}}+\beta_{2} \mathrm{~S}_{\mathrm{i}}^{2}
$$

In the plot we have also superimposed the decile boundaries (for England only) that were the definitions for the matrices of movement discussed earlier. Because of the nature of the neighbourhood scores, a move from a less advantaged neighbourhood to a more advantaged neighbourhood will reduce the change score value. The line at $\mathrm{Y}=0$ separates movers according to whether they moved to a neighbourhood that ranked higher or lower than the one they left. In general, the plot shows that those movers who begin in better neighbourhoods tend to move 'down' by moving to less advantaged places. In contrast, 
Table 5 The percentage of moving individuals by household income quartile and origin decile who move (a) up and (b) down by at least two deciles

\begin{tabular}{|c|c|c|c|c|c|c|c|c|c|c|c|}
\hline \multirow[t]{2}{*}{ Income quartile } & & \multicolumn{2}{|c|}{$\begin{array}{l}\text { More } \\
\text { advantaged }\end{array}$} & \multicolumn{6}{|l|}{ Decile } & \multicolumn{2}{|c|}{$\begin{array}{l}\text { Less } \\
\text { advantaged }\end{array}$} \\
\hline & & 1 & 2 & 3 & 4 & 5 & 6 & 7 & 8 & 9 & 10 \\
\hline \multicolumn{12}{|l|}{ (a) } \\
\hline \multirow[t]{2}{*}{ Lowest } & $\%$ & & & S.S & 13.16 & 28.24 & 26.92 & 38.50 & 32.98 & 41.40 & 35.88 \\
\hline & $\mathrm{n}$ & & & & 15 & 37 & 49 & 72 & 62 & 89 & 94 \\
\hline \multirow[t]{2}{*}{ Highest } & $\%$ & & & 17.14 & 30.36 & 50.00 & 47.73 & 57.14 & 51.72 & 59.65 & 51.22 \\
\hline & $\mathrm{n}$ & & & 24 & 34 & 38 & 42 & 40 & 30 & 34 & 21 \\
\hline \multicolumn{12}{|l|}{ (b) } \\
\hline \multirow[t]{2}{*}{ Lowest } & $\%$ & 54.12 & 43.68 & 45.05 & 29.82 & 32.06 & 24.18 & 13.90 & 10.11 & & \\
\hline & $\mathrm{n}$ & 46 & 38 & 50 & 34 & 42 & 44 & 26 & 19 & & \\
\hline \multirow[t]{2}{*}{ Highest } & $\%$ & 41.22 & 31.10 & 23.57 & 25.00 & S.S & S.S & S.S & S.S & & \\
\hline & $\mathrm{n}$ & 61 & 51 & 33 & 28 & & & & & & \\
\hline
\end{tabular}

S.S denotes fewer than 15 cases

those leaving less advantaged neighbourhoods are more likely to move 'up' to (slightly) more advantaged neighbourhoods. This partially reflects the tendency for movers to regress towards the mean when they relocate.

We can interpret the slope of the tenure lines as a measure of households' ability to move across the urban structure, as defined by deciles of advantage and disadvantage. If there was no slope then there would be no socio-spatial mobility, i.e. no change in neighbourhood quality with moves. Both slopes indicate that the rate of upward mobility increases with greater levels of disadvantage. However, housing tenure seems to play a key role in conditioning the changes in neighbourhood quality which occur with spatial mobility. Overall, homeowners from more advantaged neighbourhoods make smaller losses than social renters when they relocate. Homeowners are also more likely to make larger gains when leaving the least advantaged places. Therefore social renters living anywhere within the neighbourhood hierarchy appear to be disadvantaged when they move. A combination of lower incomes and their constrained choice set intersect to reduce the opportunities for social renters. We have omitted private renters from the graph because the confidence intervals clearly overlap with those of both homeowners and social renters. The regression line for private renters is highly curvilinear, suggesting accelerating improvements with reduced advantage, possibly as these individuals are moving into homeownership.

\subsection{Models of sorting and residential change}

We now wish to uncover the joint effects of household and housing characteristics on the spatial outcomes of residential moves. To do this requires estimating a series of panel models which account for the nesting of person-years within individuals. The variables used in these analyses are summarized in Table 7, while Tables 8 and 9 contain the blocks of models. Our previous results have shown that the level of advantage of the origin neighbourhood conditions the type of quality changes that occur with residential moves. To control for this while avoiding the use of lagged dependent variables, we estimate separate models for individuals moving out of different types of neighbourhood. We estimate 
Table 6 The percentage of moving individuals by housing tenure and origin decile who move (a) up and (b) down by at least two deciles

\begin{tabular}{|c|c|c|c|c|c|c|c|c|c|c|}
\hline \multirow{2}{*}{$\begin{array}{l}\text { Housing } \\
\text { tenure }\end{array}$} & \multicolumn{2}{|c|}{ More advantaged } & \multicolumn{6}{|c|}{ Decile } & \multicolumn{2}{|c|}{ Less advantaged } \\
\hline & 1 & 2 & 3 & 4 & 5 & 6 & 7 & 8 & 9 & 10 \\
\hline
\end{tabular}

(a)

\begin{tabular}{|c|c|c|c|c|c|c|c|c|c|c|c|}
\hline \multirow[t]{2}{*}{ Homeowner } & \multicolumn{3}{|l|}{$\%$} & 13.18 & 22.67 & 34.41 & 37.55 & 49.81 & 52.81 & 60.10 & 54.36 \\
\hline & \multicolumn{3}{|l|}{$\mathrm{n}$} & 39 & 68 & 96 & 104 & 133 & 122 & 119 & 81 \\
\hline \multirow[t]{2}{*}{ Social renter } & \multicolumn{3}{|l|}{$\%$} & S.S & S.S & S.S & 29.41 & 27.83 & 27.07 & 39.44 & 31.40 \\
\hline & \multicolumn{3}{|l|}{$\mathrm{n}$} & & & & 25 & 32 & 36 & 71 & 81 \\
\hline \multirow[t]{2}{*}{ Private renter } & \multicolumn{3}{|l|}{$\%$} & 17.14 & 17.27 & 31.71 & 29.20 & 36.45 & 36.97 & 41.90 & 38.46 \\
\hline & \multicolumn{3}{|l|}{$\mathrm{n}$} & 18 & 19 & 26 & 33 & 39 & 44 & 44 & 30 \\
\hline \multicolumn{12}{|l|}{ (b) } \\
\hline \multirow[t]{2}{*}{ Homeowner } & $\%$ & 44.88 & 32.05 & 30.74 & 27.33 & 23.30 & 15.88 & 11.61 & 8.23 & & \\
\hline & $\mathrm{n}$ & 162 & 117 & 91 & 82 & 65 & 44 & 31 & 19 & & \\
\hline \multirow[t]{2}{*}{ Social renter } & $\%$ & S.S & S.S & 44.00 & 42.50 & 36.54 & 25.88 & 17.39 & 15.79 & & \\
\hline & \multicolumn{3}{|l|}{$\mathrm{n}$} & 22 & 17 & 19 & 22 & 20 & 21 & & \\
\hline \multirow[t]{2}{*}{ Private renter } & $\%$ & 55.13 & 42.17 & 36.19 & 29.09 & 28.05 & 23.01 & 14.02 & S.S & & \\
\hline & $\mathrm{n}$ & 43 & 35 & 38 & 32 & 23 & 26 & 15 & & & \\
\hline
\end{tabular}

S.S denotes fewer than 15 cases

separate models for moves originating in the least advantaged three deciles, most advantaged three deciles and middle four deciles of neighbourhoods. This subdivision was chosen to balance the competing demands of increasing the homogeneity of origin neighbourhoods while retaining sufficient cases to provide statistical power. Subdividing the models by origin neighbourhood also enables us to investigate whether different factors affect the outcomes of moving from the least and most advantaged neighbourhoods.

Table 8 contains three random effects models where the dependent variable is the LSOA/DZ score of the destination neighbourhood. The independent variables in this analysis consist of a number of time-varying individual and household attributes, as well as time-varying contextual variables capturing changes in the local context through time (for instance changes in local house prices and regional unemployment rates). As the relationship between these factors and changes in neighbourhood quality may vary over the life course, we provide an Appendix with age-disaggregated versions of the models included in Table 8 . There is little evidence that disaggregating the models by age affects the results but Tables 10,11, 12 provide data on these models disaggregated by age. As neighbourhood quality can only change through spatial mobility, immobile cases are excluded from this analysis. Random effects models address the issue of the non-independence of observations by decomposing the error term in the regression equation into a randomly drawn individual-specific term and an idiosyncratic error term (Wooldridge 2010). This means that the random effects equation takes the following form:

$$
y_{i t}=\mu_{t}+\beta x_{i t}+\gamma z_{i}+\alpha_{i}+\varepsilon_{i t}
$$

For individual $i$ at time point $t, \beta x_{i t}$ and $\gamma z_{i}$ are vectors of coefficients on time-varying and time-constant independent variables (Allison 2009: 21). The $\alpha_{i}$ term indicates the random effects, while $\varepsilon_{i t}$ is idiosyncratic error. This specification assumes that the random effects are not correlated with any of the other independent variables. With panel data, 


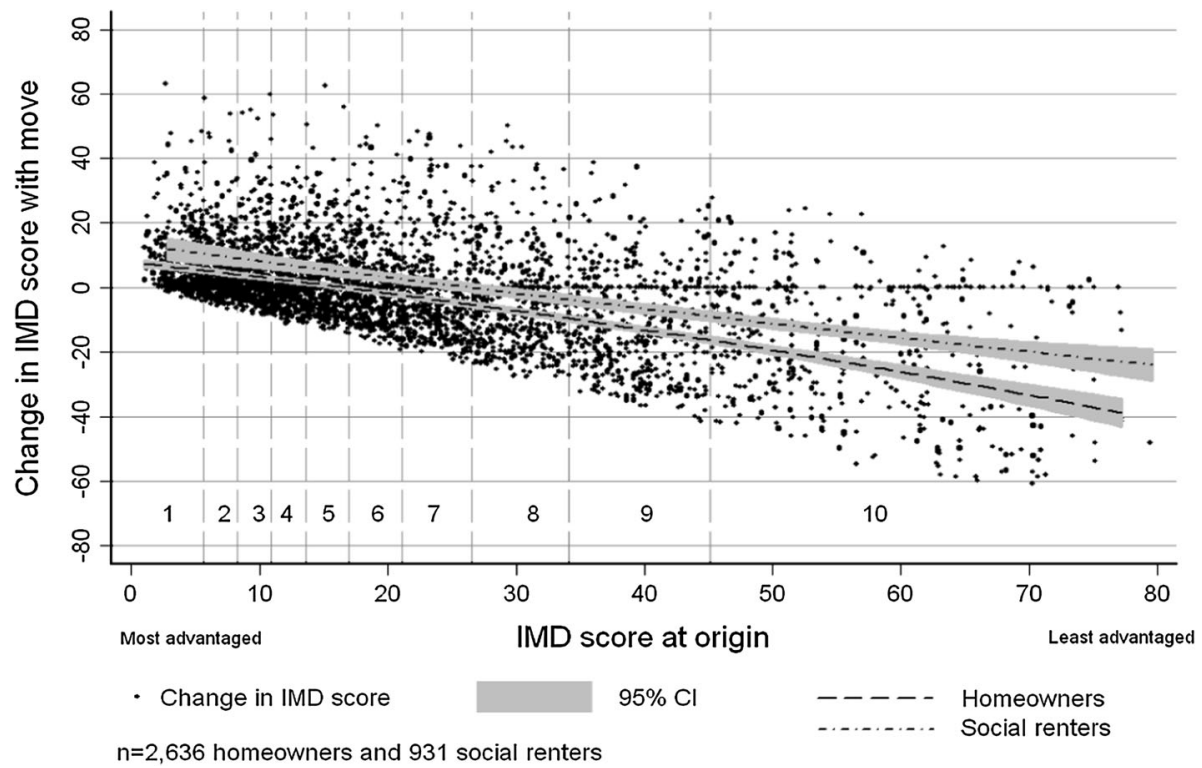

Fig. 2 Change in IMD score by IMD score of origin decile for homeowners and social renters (pooled countries with English decile lines). Note: Error introduced to protect the confidentiality of survey participants

there is also the possibility that the error terms are auto-correlated within individuals over time. As a result, we use cluster-robust standard errors in all our models. We also include period dummies in our models to control for the year in which the person was interviewed (see Table 7 for details and summary statistics).

The models in Table 8 reiterate many of the basic findings visible in the bivariate results. While age has strong links to moving propensities neither age, gender nor ethnicity have significant effects on the neighbourhood outcomes of mobility (barring the positive coefficient for age in the middle model). In contrast, partnership status is significantly associated with neighbourhood outcomes. Singles are more likely to move to less advantaged neighbourhoods than couples and there is evidence that partnership dissolution can have negative consequences for individuals outside the most advantaged neighbourhoods. Education appears strongly associated with the neighbourhood outcomes of moves. As education increases, the propensity of individuals to move to more advantaged places increases relative to individuals with little formal education. High levels of education appear to be important in effecting upward socio-spatial mobility, especially from the least advantaged neighbourhoods.

Individuals who are not employed are more likely than those who are continuously employed to move to less advantaged places. However, there are no significant effects of household income. This may be because income is both strongly correlated with education and also associated with selection into different housing tenures. The three models reinforce our argument that housing tenure structures the neighbourhood gains/losses individuals experience with spatial mobility. Moves within or into social housing are associated with worse neighbourhood outcomes than moves between owned properties. This pattern holds across the spectrum of origin neighbourhoods. These results may be due to selection (as social renters already live in less advantaged areas prior to moving), but 
Table 7 Summary statistics for the sample of movers $(n=4,097)$

\begin{tabular}{|c|c|c|}
\hline Categorical variable & Frequency & $\%$ \\
\hline \multicolumn{3}{|l|}{ Decile of origin neighbourhood } \\
\hline Most advantaged & 402 & 9.81 \\
\hline 2 & 415 & 10.13 \\
\hline 3 & 405 & 9.89 \\
\hline 4 & 388 & 9.47 \\
\hline 5 & 368 & 8.98 \\
\hline 6 & 411 & 10.03 \\
\hline 7 & 436 & 10.64 \\
\hline 8 & 422 & 10.30 \\
\hline 9 & 423 & 10.32 \\
\hline Least advantaged & 427 & 10.42 \\
\hline Female dummy (ref male) & 2,352 & 57.41 \\
\hline Non-white ethnic minority dummy (ref white) & 123 & 3.00 \\
\hline \multicolumn{3}{|l|}{ Partnership status $t$ to $t+1$ (ref remain couple) } \\
\hline Remain single (not cohabiting or married) & 1,222 & 29.83 \\
\hline Enter couple & 375 & 9.15 \\
\hline Exit couple & 285 & 6.96 \\
\hline \multicolumn{3}{|l|}{ Change in $\mathrm{n}$ children under $16 t$ to $t+1$ (ref children never present) } \\
\hline Same number of children & 1,188 & 29.00 \\
\hline Increased number of children & 285 & 6.96 \\
\hline Decreased number of children & 254 & 6.20 \\
\hline \multicolumn{3}{|l|}{ Education level (ref very low qualifications) } \\
\hline Low (basic secondary school level e.g. GCSE) & 1,014 & 24.75 \\
\hline Medium (higher school/further education qualifications e.g. A level) & 1,542 & 37.64 \\
\hline High (university degree and above) & 654 & 15.96 \\
\hline \multicolumn{3}{|l|}{ Change in employment status $t$ to $t+1$ (ref always employed) } \\
\hline Not employed & 1,270 & 31.00 \\
\hline Enter employment & 192 & 4.69 \\
\hline Exit employment & 249 & 6.08 \\
\hline \multicolumn{3}{|l|}{ Housing tenure change $t$ to $t+1$ (ref remain owner) } \\
\hline Remain social renter & 557 & 13.60 \\
\hline Remain private renter & 374 & 9.13 \\
\hline Own-social rent & 155 & 3.78 \\
\hline Own-private rent & 361 & 8.81 \\
\hline Social rent-own & 148 & 3.61 \\
\hline Social rent-private rent & 120 & 2.93 \\
\hline Private rent-own & 379 & 9.25 \\
\hline Private rent-social rent & 142 & 3.47 \\
\hline Moved $>30 \mathrm{~km}$ dummy (ref moved $<30 \mathrm{~km}$ ) & 677 & 16.52 \\
\hline \multicolumn{3}{|l|}{ Year of interview (ref 2007-2008) } \\
\hline 1991-1992 & 612 & 14.94 \\
\hline 1993-1994 & 552 & 13.47 \\
\hline 1995-1996 & 494 & 12.06 \\
\hline
\end{tabular}


Table 7 continued

\begin{tabular}{|c|c|c|c|}
\hline Categorical variable & Frequency & & $\%$ \\
\hline 1997-1998 & 417 & & 10.18 \\
\hline 1999-2000 & 531 & & 12.96 \\
\hline $2001-2002$ & 590 & & 14.40 \\
\hline 2003-2004 & 400 & & 9.76 \\
\hline 2005-2006 & 372 & & 9.08 \\
\hline Continuous variable & & Mean & $\mathrm{SD}$ \\
\hline Age & & 42.76 & 15.60 \\
\hline Real household income $£ / 10,000$ (2005 prices) & & 2.70 & 2.13 \\
\hline Mean real local authority house prices (2005 prices) & & 100.26 & 51.59 \\
\hline Regional unemployment rate (16-64 year olds) & & 7.04 & 2.27 \\
\hline$\%$ social renting in region & & 22.29 & 6.29 \\
\hline
\end{tabular}

they also imply that a reliance on social housing channels people into the least advantaged places. Exiting the social or private rental sector for homeownership is also associated with worse outcomes for movers originating in the least advantaged neighbourhoods. This indicates that people may accept a lower quality of neighbourhood in order to attain homeownership, a finding which is consistent with a long-term push towards a 'homeownership society'.

As long-distance migration may have different associations with neighbourhood quality changes than local residential mobility, the models in Table 8 contain a dummy variable disaggregating moves into those less than and greater than $30 \mathrm{~km}$. We experimented with alternative distance thresholds, but the results did not alter markedly. The coefficients on this dummy suggest that longer distance moves lead to changes of greater magnitude than shorter distance moves. This may be a function of unfamiliarity as households take time to know a new environment and find the "best" neighbourhood and house that suits their needs. Higher local house prices are associated with gains in neighbourhood quality while higher unemployment rates generally increase the deprivation scores of movers. Somewhat unexpectedly, higher levels of social housing in the region are associated with gains in neighbourhood quality with residential mobility.

Finally, we estimate a set of fixed effects models where the dependent variable is the IMD score of the neighbourhood the person lives in (Table 9). As in Table 8, we include a variety of time-varying and time-constant individual, household and contextual variables in these models. Fixed effects models allow us to control for unobserved but time-constant heterogeneity by focusing only on the variance in neighbourhood quality over time within individuals (Allison 2009). This is achieved through time-demeaning the data, expressing the dependent and independent variables as deviations from their person-specific means (Allison 2009). Unlike random effects models, the fixed effects framework therefore enables us to control for selection, which in our case may occur if certain types of individuals and households are more likely to relocate than others (see Korpi et al. 2010 for a migration example). By including an individual level fixed effect for every person, fixed effects models do not allow us to estimate parameters for independent variables which are (largely) constant over time (such as gender, ethnicity or education). As only movers can experience changes in neighbourhood quality, the coefficients can be interpreted as the effects of within-person changes on each independent variable on the neighbourhood outcomes of residential moves. 


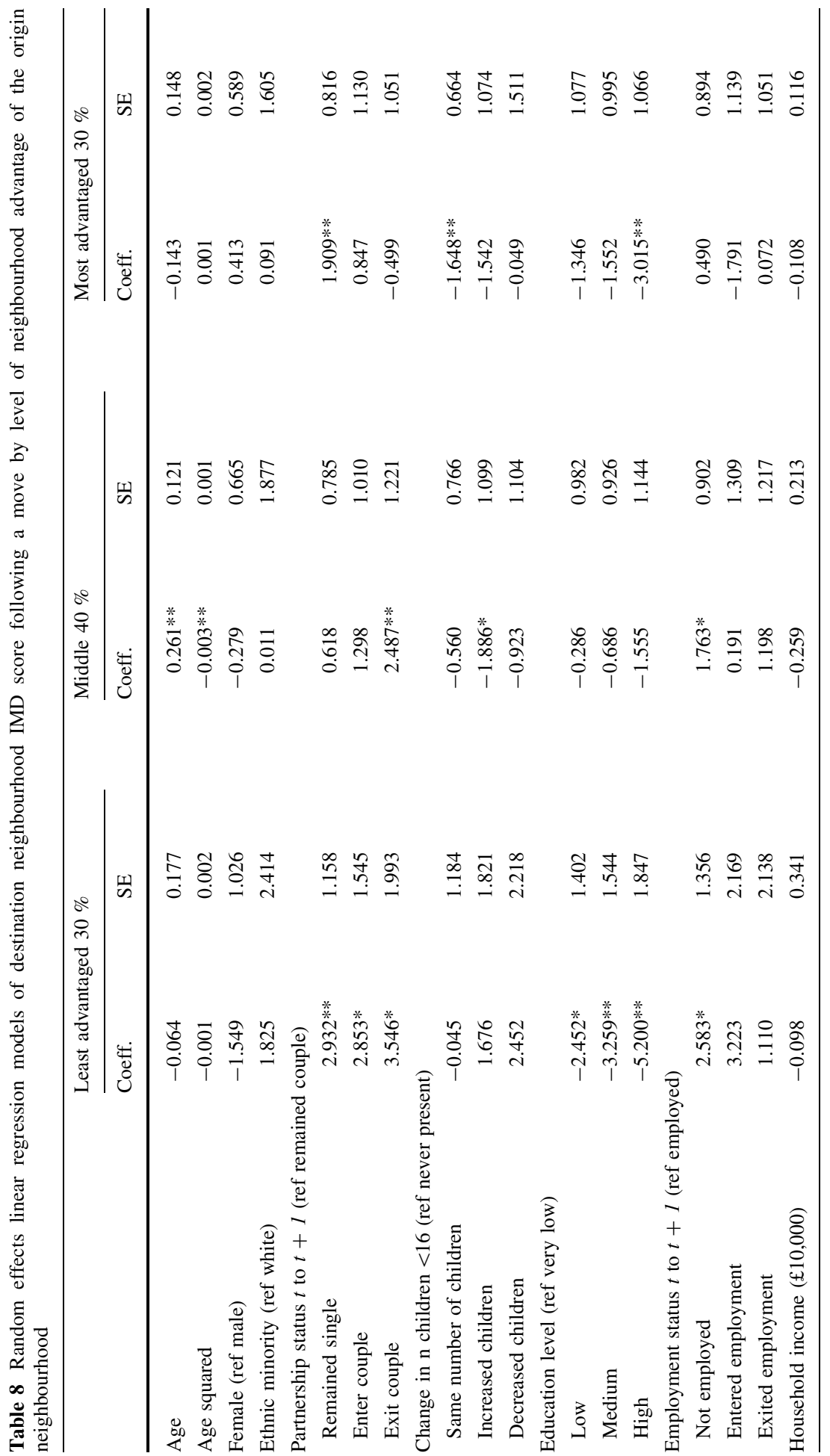




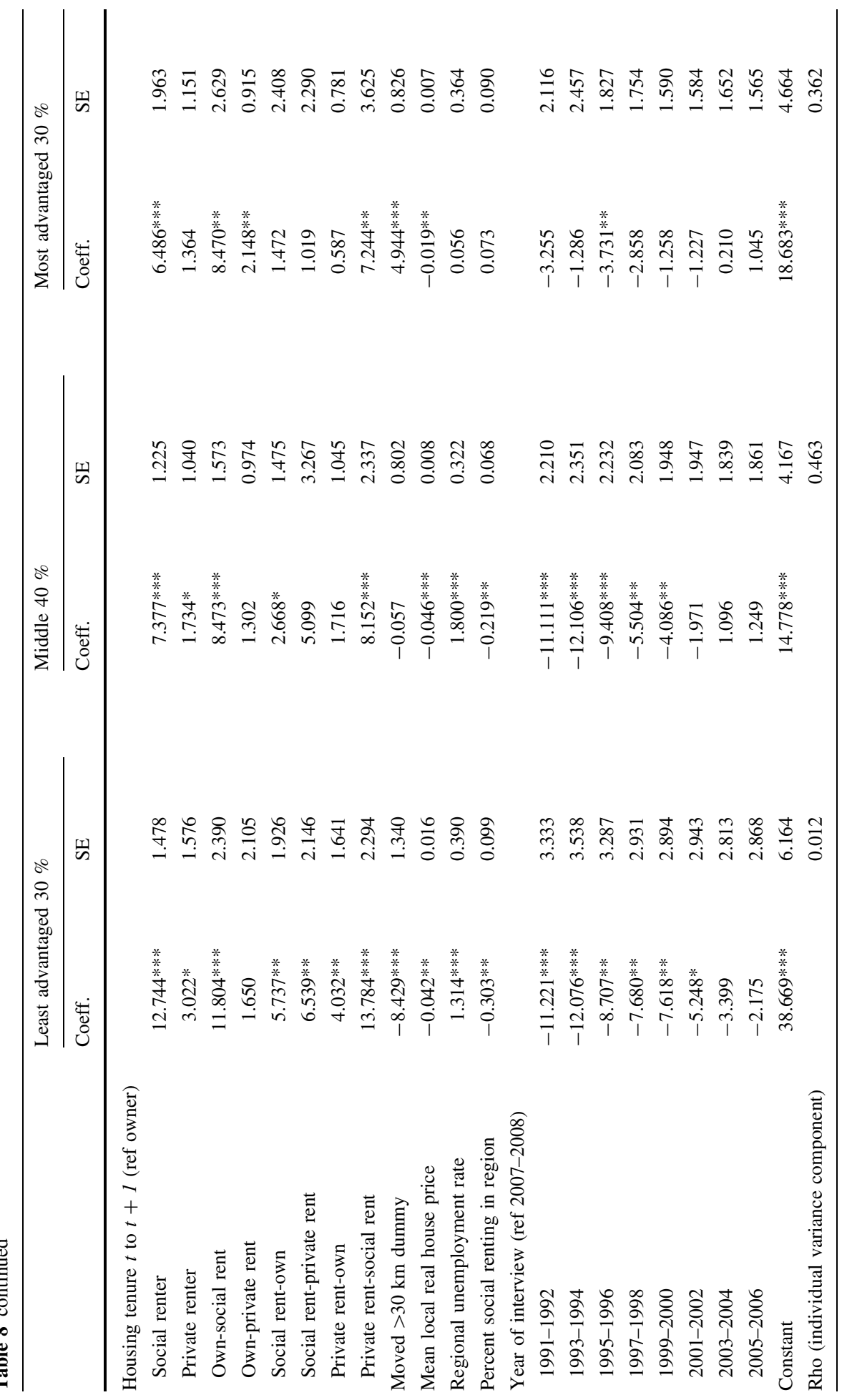




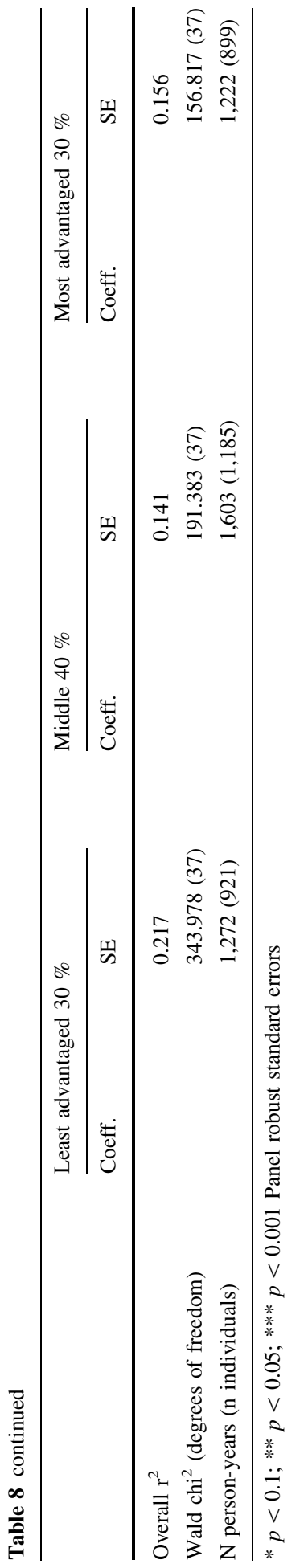


Table 9 Fixed effects linear regression models of neighbourhood IMD score by level of neighbourhood advantage at the previous wave

\begin{tabular}{|c|c|c|c|c|c|c|}
\hline & \multicolumn{2}{|c|}{$\begin{array}{l}\text { Least advantaged } \\
30 \%\end{array}$} & \multicolumn{2}{|l|}{ Middle $40 \%$} & \multicolumn{2}{|c|}{$\begin{array}{l}\text { Most advantaged } \\
30 \%\end{array}$} \\
\hline & Coeff. & SE & Coeff. & SE & Coeff & SE \\
\hline \multicolumn{7}{|l|}{ Residential move (ref no move) } \\
\hline Moved $\leq 30 \mathrm{~km}$ & $-7.669 * * *$ & 0.466 & $0.534 *$ & 0.286 & $3.376^{* * *}$ & 0.244 \\
\hline Moved $>30 \mathrm{~km}$ & $-18.088^{* * *}$ & 1.524 & 0.236 & 0.697 & $6.665^{* * *}$ & 0.722 \\
\hline Age & $-0.192 * *$ & 0.087 & $0.084 * *$ & 0.042 & $0.086^{* *}$ & 0.038 \\
\hline Age squared & $0.001 * *$ & 0.001 & 0.000 & 0.000 & -0.000 & 0.000 \\
\hline Couple (ref single) & $-1.206^{* *}$ & 0.399 & $-0.525^{* *}$ & 0.189 & -0.040 & 0.147 \\
\hline $\mathrm{N}$ children $<16$ & -0.203 & 0.218 & $-0.274 * * *$ & 0.067 & $-0.125^{*}$ & 0.072 \\
\hline \multicolumn{7}{|c|}{ Employment status (ref employed) } \\
\hline Unemployed & -0.264 & 0.323 & 0.220 & 0.190 & 0.079 & 0.243 \\
\hline Out of labour force & -0.095 & 0.254 & 0.061 & 0.102 & -0.099 & 0.068 \\
\hline $\begin{array}{l}\text { Real household income } \\
\quad(£ 10,000)\end{array}$ & $-0.154 * *$ & 0.056 & $-0.043^{* *}$ & 0.020 & $-0.019 * *$ & 0.009 \\
\hline \multicolumn{7}{|l|}{ Housing tenure (ref homeowner) } \\
\hline Social renter & $2.075 * *$ & 0.636 & $1.495 * * *$ & 0.387 & $2.347 * * *$ & 0.627 \\
\hline Private renter & $-1.493^{*}$ & 0.796 & -0.175 & 0.374 & $1.144 * *$ & 0.397 \\
\hline $\begin{array}{l}\text { Mean local real house price } \\
(£ 1,000)\end{array}$ & $-0.010 *$ & 0.005 & $-0.015 * * *$ & 0.002 & $-0.006 * *$ & 0.002 \\
\hline Regional unemployment rate & 0.035 & 0.114 & -0.052 & 0.048 & 0.054 & 0.048 \\
\hline$\%$ social renting in region & $0.176^{*}$ & 0.093 & $0.114 * *$ & 0.041 & 0.045 & 0.045 \\
\hline Constant & $44.601 * * *$ & 4.667 & $13.027 * * *$ & 2.359 & 2.168 & 2.149 \\
\hline $\begin{array}{l}\text { Rho (Individual level variance } \\
\text { component) }\end{array}$ & 0.866 & & 0.832 & & 0.813 & \\
\hline Within $r^{2}$ & 0.201 & & 0.022 & & 0.199 & \\
\hline Degrees of freedom & 21 & & 21 & & 21 & \\
\hline $\mathrm{N}$ person-years ( $\mathrm{n}$ individuals) & $19,717(2,573)$ & & $29,488(3,573)$ & & $22,925(2,626)$ & \\
\hline
\end{tabular}

Extra controls included for year of interview (parameters not shown). Panel robust standard errors $* p<0.1 ; * * p<0.05 ; * * * p<0.001$

Paralleling the results from Table 3 and Fig. 2, we find that moves from the least advantaged areas are associated with gains in neighbourhood quality. In contrast, moves from the upper third of neighbourhoods typically involve reductions in quality. Increases in age and entering a partnership are associated with moves to more advantaged neighbourhoods for people living in the least advantaged places. Interestingly, increasing age leads to small reductions in neighbourhood quality for movers from the most advantaged $70 \%$ of neighbourhoods. Increasing numbers of children seems to be linked to improvements in neighbourhood quality for individuals living in the middle ranked and most advantaged neighbourhoods. Taken together, these findings indicate that many people move to improve their neighbourhood quality when forming new households or expanding their families.

Rising household income is associated with improvements in neighbourhood quality for individuals across the neighbourhood hierarchy, although most noticeably for movers from the least advantaged places. That no significant effects of household income were found in the random effects models indicates that individuals with higher incomes may have already 
selected themselves into more advantaged places prior to moving. As expected from our previous results and the findings of Rabe and Taylor (2010), moves from homeownership into social renting lead to reductions in neighbourhood quality with mobility. This seems to be the case regardless of initial neighbourhood type. Moves into private renting from homeownership are associated with neighbourhood gains for those living in the least advantaged places and quality losses for those in the most advantaged places. This may be because of the great diversity within the British private rental sector. Overall, both sets of models confirm that housing tenure plays a strong role in conditioning the neighbourhood outcomes of residential mobility.

\section{Conclusions and observations}

Our analysis extends previous work on processes of movement across the socio-spatial hierarchy. Previously, the focus was often on the difficulty of leaving poor neighbourhoods and studies often focused solely on those in poverty and those living in poor neighbourhoods (Robson et al. 2008). Our models, which cover the entire spectrum of neighbourhoods, provide a much richer and more holistic interpretation of the process of mobility across sociospatial structures. While to some extent there are no major surprises, this approach allows us to show that there is considerable movement across the hierarchy of places. Our results also show how the underlying housing structure conditions socio-spatial mobility.

As might be anticipated from social mobility debates, individual education and household income are defining associates of the ability to overcome the structural constraints of the housing market and make socio-spatial gains with mobility. Importantly however, the results also show that both neighbourhood characteristics and housing tenure clearly structure the neighbourhood outcomes associated with residential moves. Both findings point to structural inequality in British society and to the difficulty of overcoming that embedded inequality. Those living at the bottom of the neighbourhood hierarchy have real difficulty in advancing their socio-spatial position through mobility, especially when combined with lower incomes and fewer qualifications. At the same time we know that the wide range of neighbourhood types in the lowest decile can enable some upward mobility even if the households cannot make a decile change. With new data from the UK Understanding Society panel survey we will soon be able to explore the extent to which changes within the most disadvantaged decile are 'moves which improve' rather than residential churn.

Although we know a good deal about how housing tenure conditions mobility, this study enriches our understanding of how tenure can work at a macro scale and by advancing or inhibiting particular kinds of social change. Tenure changes are the most important and significant predictors of neighbourhood mobility, with becoming a social renter almost by definition leading to moves down the neighbourhood hierarchy. This disproportionately penalizes the most economically marginalized households who are reliant on social housing (Burrows 1999), as tenure structures force them into the most deprived and opportunity poor communities. If one believes in neighbourhood effects, then the poor are disadvantaged both by being poor and through their tendency to end up in the most disadvantaged places, regardless of whether housing is allocated through market or non-market mechanisms. The results emphasize that in the UK the socio-spatial hierarchy, and the opportunities to move to better places, is highly stratified by housing tenure.

In the UK, the impact of the on-going global economic crisis has reinvigorated debate about social opportunity structures. In this context, it is often argued that a society which provides opportunities for individuals to move up the social, occupational and economic 
ladders is a society which is more egalitarian than a society which provides barriers and constraints to movement through the social hierarchy. But, even if there are no formal barriers to social mobility, the attainment of individuals may still be constrained by a cocktail of personal and geographic factors. Investigating whether and how various individual, household and contextual factors influence the socio-spatial mobility of individuals has been the central concern of this paper.

Acknowledgments The research reported in this paper was made possible through the financial support of the EU (NBHCHOICE Career Integration Grant under FP7-PEOPLE-2011-CIG), and of the UK Economic and Social Research Council (ESRC RES-074-27-0020).

\section{Appendix}

See Tables 10, 11, 12.

Table 10 Age disaggregated random effects models of neighbourhood deprivation after a move from the least advantaged $30 \%$ of neighbourhoods

\begin{tabular}{|c|c|c|c|c|c|c|}
\hline & \multicolumn{2}{|l|}{ Full sample } & \multicolumn{2}{|l|}{ Under 35} & \multicolumn{2}{|l|}{35 and over } \\
\hline & Coeff & SE & Coeff & SE & Coeff & SE \\
\hline Age & -0.064 & 0.177 & -0.803 & 2.128 & -0.045 & 0.349 \\
\hline Age squared & -0.001 & 0.002 & 0.012 & 0.039 & -0.001 & 0.003 \\
\hline Female dummy & -1.549 & 1.026 & -1.879 & 1.617 & -1.486 & 1.318 \\
\hline $\begin{array}{l}\text { Ethnic minority dummy (ref } \\
\text { ethnic) }\end{array}$ & 1.825 & 2.414 & -0.607 & 2.813 & 5.767 & 4.209 \\
\hline \multicolumn{7}{|c|}{ Couple status $t$ to $t+1$ (ref couple) } \\
\hline Remained single & $2.932 * *$ & 1.158 & $4.836^{* *}$ & 1.887 & 2.077 & 1.486 \\
\hline Entered couple & $2.853^{*}$ & 1.545 & $5.971 * *$ & 2.179 & -1.384 & 2.251 \\
\hline Exited couple & $3.546^{*}$ & 1.993 & 4.006 & 2.609 & 3.905 & 3.236 \\
\hline \multicolumn{7}{|c|}{ Presence of children $t$ to $t+1$ (ref never) } \\
\hline Same number of children & -0.045 & 1.184 & 2.047 & 1.918 & 0.500 & 1.765 \\
\hline Increased children & 1.676 & 1.821 & 3.600 & 2.581 & 3.754 & 2.862 \\
\hline Decreased children & 2.452 & 2.218 & 6.054 & 4.149 & 1.425 & 2.465 \\
\hline \multicolumn{7}{|l|}{ Education level (ref v low) } \\
\hline Low & $-2.452^{*}$ & 1.402 & -1.397 & 2.480 & -2.505 & 1.687 \\
\hline Medium & $-3.259 * *$ & 1.544 & -2.544 & 2.676 & $-3.699 * *$ & 1.885 \\
\hline High & $-5.200 * *$ & 1.847 & $-5.609^{*}$ & 3.098 & $-4.347^{*}$ & 2.542 \\
\hline \multicolumn{7}{|c|}{ Employment status $t$ to $t+1$ (ref emp.) } \\
\hline Not employed & $2.583^{*}$ & 1.356 & 2.612 & 2.378 & 2.472 & 1.708 \\
\hline Entered employment & 3.223 & 2.169 & -0.256 & 2.700 & $10.106^{* *}$ & 4.069 \\
\hline Exited employment & 1.110 & 2.138 & 1.611 & 2.982 & 0.529 & 2.916 \\
\hline Household income/10,000 & -0.098 & 0.341 & -0.352 & 0.552 & -0.192 & 0.404 \\
\hline \multicolumn{7}{|c|}{ Housing tenure $t$ to $t+1$ (ref owner) } \\
\hline Social renter & $12.744 * * *$ & 1.478 & $9.297 * * *$ & 2.546 & $13.603 * * *$ & 1.767 \\
\hline Private renter & $3.022 *$ & 1.576 & 2.523 & 2.380 & 1.646 & 2.344 \\
\hline Own-social rent & $11.804 * * *$ & 2.390 & 7.001 & 5.621 & $12.195^{* * *}$ & 2.753 \\
\hline Own-private rent & 1.650 & 2.105 & 3.066 & 3.406 & 0.152 & 2.482 \\
\hline Social rent-own & $5.737 * *$ & 1.926 & 1.360 & 3.039 & $7.857 * *$ & 2.490 \\
\hline
\end{tabular}


Table 10 continued

\begin{tabular}{|c|c|c|c|c|c|c|}
\hline & \multicolumn{2}{|l|}{ Full sample } & \multicolumn{2}{|l|}{ Under 35} & \multicolumn{2}{|l|}{35 and over } \\
\hline & Coeff & SE & Coeff & SE & Coeff & SE \\
\hline Social rent-rent & $6.539 * *$ & 2.146 & 3.899 & 3.369 & $7.385 * *$ & 2.930 \\
\hline Private rent-own & $4.032 * *$ & 1.641 & $6.565^{* *}$ & 2.086 & -1.538 & 2.381 \\
\hline Private rent-social rent & $13.784 * * *$ & 2.294 & $13.140 * * *$ & 3.318 & $13.052 * * *$ & 3.090 \\
\hline Moved $>30 \mathrm{~km}$ dummy & $-8.429 * * *$ & 1.340 & $-6.582 * *$ & 2.077 & $-9.930 * * *$ & 1.587 \\
\hline Mean local house price/1,000 (£) & $-0.042 * *$ & 0.016 & -0.023 & 0.038 & $-0.040 * *$ & 0.016 \\
\hline Regional unemployment rate & $1.314 * * *$ & 0.390 & $1.366^{* *}$ & 0.583 & $0.987 *$ & 0.576 \\
\hline$\%$ stock social rented in region & $-0.303^{* *}$ & 0.099 & -0.198 & 0.146 & $-0.325 * *$ & 0.144 \\
\hline \multicolumn{7}{|l|}{ Year of interview (ref 2007-2008) } \\
\hline $1991-1992$ & $-11.221 * * *$ & 3.333 & $-22.870^{* *}$ & 7.093 & -5.669 & 4.043 \\
\hline 1993-1994 & $-12.076^{* * *}$ & 3.538 & $-20.871^{* *}$ & 7.618 & $-10.458 * *$ & 4.131 \\
\hline 1995-1996 & $-8.707 * *$ & 3.287 & $-16.263^{* *}$ & 6.982 & $-9.049 * *$ & 3.739 \\
\hline 1997-1998 & $-7.680 * *$ & 2.931 & $-16.184 * *$ & 6.833 & $-8.028 * *$ & 3.256 \\
\hline 1999-2000 & $-7.618^{* *}$ & 2.894 & $-17.308^{* *}$ & 6.743 & $-7.081 * *$ & 3.179 \\
\hline 2001-2002 & $-5.248^{*}$ & 2.943 & $-13.651 * *$ & 6.354 & $-5.741^{*}$ & 3.099 \\
\hline 2003-2004 & -3.399 & 2.813 & $-11.926^{*}$ & 6.542 & -3.318 & 3.028 \\
\hline 2005-2006 & -2.175 & 2.868 & $-13.209 *$ & 7.195 & -1.648 & 3.140 \\
\hline Constant & $38.669 * * *$ & 6.164 & $52.795^{*}$ & 29.893 & $41.113 * * *$ & 11.557 \\
\hline Rho & 0.012 & & 0.154 & & 0.045 & \\
\hline Overall $r^{2}$ & 0.217 & & 0.218 & & 0.259 & \\
\hline $\mathrm{Chi}^{2}$ & 343.978 & & 159.093 & & 290.065 & \\
\hline Degrees of freedom & 37.000 & & 37.000 & & 37.000 & \\
\hline $\mathrm{N}$ & $1,272.000$ & & 529.000 & & 743.000 & \\
\hline $\mathrm{N}$ clusters & 921.000 & & 358.000 & & 605.000 & \\
\hline
\end{tabular}

$* p<0.1 ; * * p<0.05 ; * * * p<0.001$. Panel robust standard errors

Table 11 Age disaggregated random effects models of neighbourhood deprivation after a move from the middle $40 \%$ of neighbourhoods

\begin{tabular}{|c|c|c|c|c|c|c|}
\hline & \multicolumn{2}{|c|}{ Full sample } & \multicolumn{2}{|c|}{ Under 35} & \multicolumn{2}{|l|}{35 and over } \\
\hline & Coeff & SE & Coeff & SE & Coeff & SE \\
\hline Age & $0.261 * *$ & 0.121 & -0.036 & 1.452 & 0.310 & 0.231 \\
\hline Age squared & $-0.003 * *$ & 0.001 & 0.001 & 0.026 & $-0.004 *$ & 0.002 \\
\hline Female dummy & -0.279 & 0.665 & -0.716 & 1.152 & 0.014 & 0.839 \\
\hline Ethnic minority dummy (ref white) & 0.011 & 1.877 & -0.531 & 3.025 & 0.370 & 2.132 \\
\hline \multicolumn{7}{|l|}{ Couple status $t$ to $t+1$ (ref couple) } \\
\hline Remained single & 0.618 & 0.785 & 0.941 & 1.430 & 0.448 & 0.930 \\
\hline Entered couple & 1.298 & 1.010 & 1.299 & 1.506 & 0.759 & 1.411 \\
\hline Exited couple & $2.487 * *$ & 1.221 & 1.282 & 2.014 & 2.591 & 1.583 \\
\hline \multicolumn{7}{|c|}{ Presence of children $t$ to $t+1$ (ref never) } \\
\hline Same number of children & -0.560 & 0.766 & -1.155 & 1.263 & 0.103 & 1.060 \\
\hline Increased children & $-1.886^{*}$ & 1.099 & -1.725 & 1.697 & -1.977 & 1.426 \\
\hline
\end{tabular}


Table 11 continued

\begin{tabular}{|c|c|c|c|c|c|c|}
\hline & \multicolumn{2}{|l|}{ Full sample } & \multicolumn{2}{|l|}{ Under 35} & \multicolumn{2}{|l|}{35 and over } \\
\hline & Coeff & SE & Coeff & SE & Coeff & SE \\
\hline Decreased children & -0.923 & 1.104 & 2.096 & 2.503 & -1.619 & 1.295 \\
\hline \multicolumn{7}{|l|}{ Education level (ref very low) } \\
\hline Low & -0.286 & 0.982 & -1.102 & 2.207 & -0.535 & 1.127 \\
\hline Medium & -0.686 & 0.926 & -3.381 & 2.107 & 0.433 & 1.040 \\
\hline High & -1.555 & 1.144 & -3.286 & 2.433 & -1.795 & 1.325 \\
\hline \multicolumn{7}{|c|}{ Employment status $t$ to $t+1$ (ref emp.) } \\
\hline Not employed & $1.763^{*}$ & 0.902 & 0.995 & 1.560 & $2.211^{*}$ & 1.140 \\
\hline Entered employment & 0.191 & 1.309 & -0.550 & 2.046 & 1.562 & 2.021 \\
\hline Exited employment & 1.198 & 1.217 & 1.387 & 2.125 & 1.050 & 1.517 \\
\hline Household income & -0.259 & 0.213 & 0.199 & 0.263 & $-0.594 * * *$ & 0.154 \\
\hline \multicolumn{7}{|c|}{ Housing tenure $t$ to $t+1$ (ref owner) } \\
\hline Social renter & $7.377 * * *$ & 1.225 & $5.100 * *$ & 2.136 & $8.991 * * *$ & 1.462 \\
\hline Private renter & $1.734^{*}$ & 1.040 & 1.819 & 1.584 & 2.011 & 1.410 \\
\hline Own-social rent & $8.473 * * *$ & 1.573 & $11.028 * *$ & 3.453 & $7.993 * * *$ & 1.708 \\
\hline Own-private rent & 1.302 & 0.974 & 1.757 & 1.711 & 1.532 & 1.171 \\
\hline Social rent-own & $2.668^{*}$ & 1.475 & 0.785 & 2.407 & 2.645 & 1.797 \\
\hline Social rent-private rent & 5.099 & 3.267 & -0.442 & 3.146 & $10.277 * *$ & 4.612 \\
\hline Private rent-own & 1.716 & 1.045 & 2.049 & 1.763 & 1.113 & 1.202 \\
\hline Private rent-social rent & $8.152 * * *$ & 2.337 & 5.287 & 3.599 & $11.448 * * *$ & 3.165 \\
\hline Moved >30 km dummy & -0.057 & 0.802 & -1.232 & 1.463 & 0.698 & 0.969 \\
\hline Mean local house price $(£ 1,000)$ & $-0.046 * * *$ & 0.008 & $-0.047 * *$ & 0.017 & $-0.049 * * *$ & 0.009 \\
\hline Regional unemployment rate & $1.800^{* * *}$ & 0.322 & $1.769 * * *$ & 0.524 & $1.930 * * *$ & 0.433 \\
\hline$\%$ stock social rented in region & $-0.219 * *$ & 0.068 & $-0.181^{*}$ & 0.102 & $-0.282^{* *}$ & 0.097 \\
\hline \multicolumn{7}{|l|}{ Year of interview (ref 2007-2008) } \\
\hline $1991-1992$ & $-11.111 * * *$ & 2.210 & $-11.204 * *$ & 5.193 & $-12.563 * * *$ & 2.553 \\
\hline 1993-1994 & $-12.106 * * *$ & 2.351 & $-11.663 * *$ & 5.397 & $-14.095 * * *$ & 2.724 \\
\hline 1995-1996 & $-9.408 * * *$ & 2.232 & $-9.436^{*}$ & 5.198 & $-10.600 * * *$ & 2.492 \\
\hline $1997-1998$ & $-5.504 * *$ & 2.083 & -5.325 & 5.010 & $-5.910 * *$ & 2.284 \\
\hline 1999-2000 & $-4.086^{* *}$ & 1.948 & -5.816 & 4.909 & $-4.017 *$ & 2.117 \\
\hline 2001-2002 & -1.971 & 1.947 & -3.581 & 4.901 & -2.042 & 2.125 \\
\hline 2003-2004 & 1.096 & 1.839 & 1.581 & 4.740 & 0.598 & 1.955 \\
\hline 2005-2006 & 1.249 & 1.861 & 2.802 & 4.975 & 0.484 & 1.958 \\
\hline Constant & $14.778 * * *$ & 4.167 & 20.719 & 19.971 & $15.352 * *$ & 7.230 \\
\hline Rho & 0.463 & & 0.433 & & 0.555 & \\
\hline Overall $\mathrm{r}^{2}$ & 0.141 & & 0.122 & & 0.180 & \\
\hline $\mathrm{Chi}^{2}$ & 191.383 & & 70.748 & & 190.791 & \\
\hline Degrees of freedom & 37.000 & & 37.000 & & 37.000 & \\
\hline $\mathrm{N}$ & $1,603.000$ & & 594.000 & & $1,009.000$ & \\
\hline $\mathrm{N}$ clusters & $1,185.000$ & & 427.000 & & 811.000 & \\
\hline
\end{tabular}

$* p<0.1$; ** $p<0.05$; *** $p<0.001$. Panel robust standard errors 
Table 12 Age disaggregated random effects models of neighbourhood deprivation after a move from the most advantaged $30 \%$ of neighbourhoods

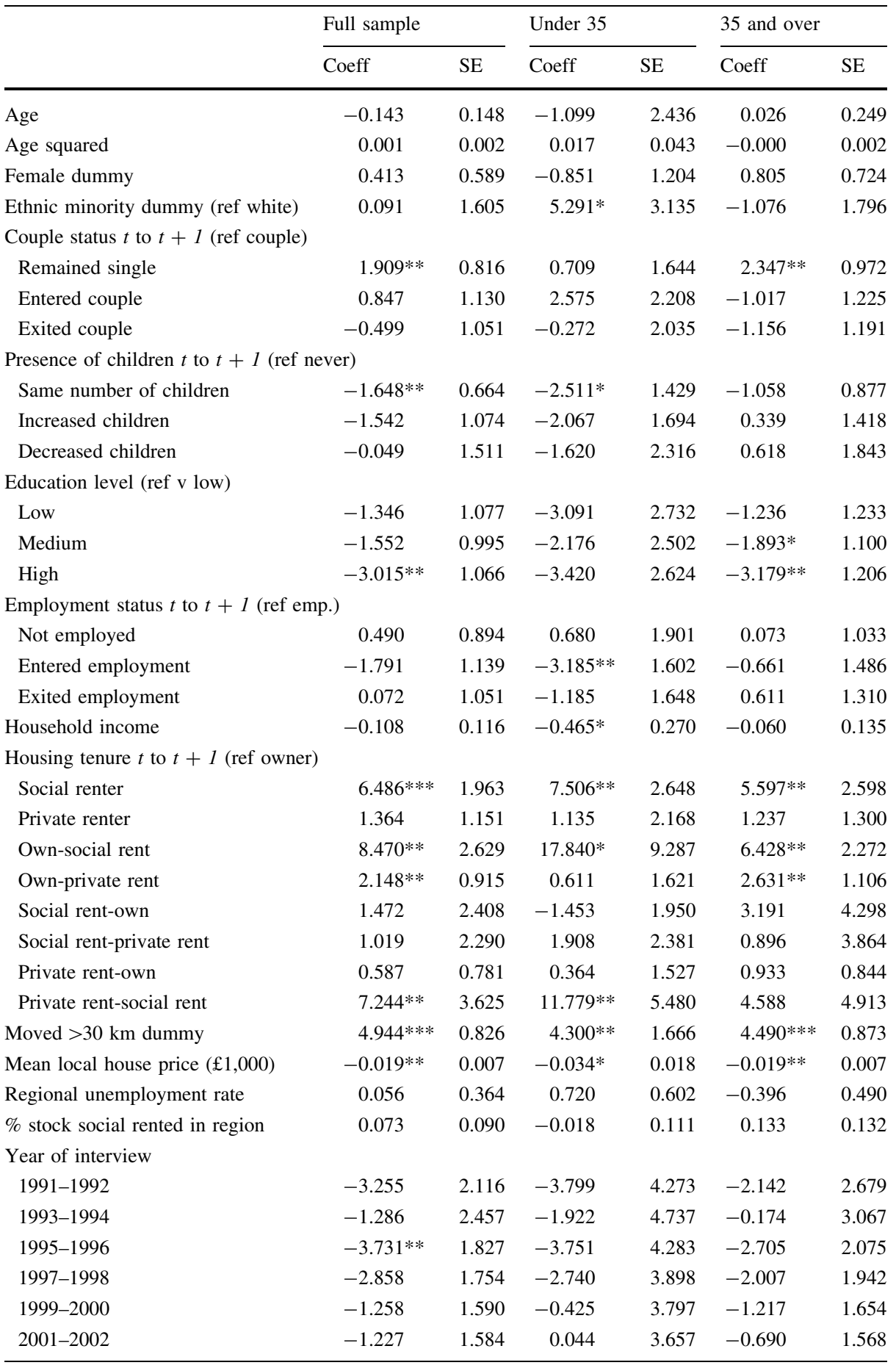


Table 12 continued

\begin{tabular}{|c|c|c|c|c|c|c|}
\hline & \multicolumn{2}{|l|}{ Full sample } & \multicolumn{2}{|l|}{ Under 35} & \multicolumn{2}{|c|}{35 and over } \\
\hline & Coeff & SE & Coeff & SE & Coeff & SE \\
\hline 2003-2004 & 0.210 & 1.652 & 2.497 & 4.164 & -0.068 & 1.704 \\
\hline 2005-2006 & 1.045 & 1.565 & 5.356 & 3.574 & 0.444 & 1.576 \\
\hline Constant & $18.683 * * *$ & 4.664 & 33.786 & 35.311 & $14.588^{*}$ & 7.698 \\
\hline Rho & 0.362 & & 0.235 & & 0.452 & \\
\hline Overall $r^{2}$ & 0.156 & & 0.232 & & 0.150 & \\
\hline $\mathrm{Chi}^{2}$ & 156.817 & & 111.907 & & 130.372 & \\
\hline Degrees of freedom & 37.000 & & 37.000 & & 37.000 & \\
\hline $\mathrm{N}$ & $1,222.000$ & & 373.000 & & 849.000 & \\
\hline $\mathrm{N}$ clusters & 899.000 & & 282.000 & & 675.000 & \\
\hline
\end{tabular}

$* p<0.1 ; * * p<0.05 ; * * * p<0.001$. Panel robust standard errors

\section{References}

Allison, P. D. (2009). Fixed effects regression models. Thousand Oaks, CA: Sage.

Bailey, N., \& Livingston, M. (2007). Population turnover and area deprivation. Bristol: Policy Press.

Bailey, N., \& Livingston, M. (2008). Selective migration and area deprivation: Evidence from 2001 census migration data for England and Scotland. Urban Studies, 45(4), 943-961.

Boheim, R., \& Taylor, M. (2002). Tied down or room to move? Investigating the relationship between housing tenure, employment status and residential mobility in Britain. Scottish Journal of Political Economy, 49, 369-392.

Bolt, G., van Kempen, R., \& van Ham, M. (2008). Minority ethnic groups in the Dutch housing market: Spatial segregation, relocation dynamics and housing policy. Urban Studies, 45, 1359-1384.

Breen, R. (Ed.). (2004). Social mobility in Europe. Oxford: Oxford University Press.

Buck, N. (2000). Using panel surveys to study migration and residential mobility. In D. Rose (Ed.), Researching social and economic change: The uses of household panel studies. London: Routledge.

Burrows, R. (1999). Residential mobility and residualisation in social housing in England. Journal of Social Policy, 28, 27-52.

Cabinet Office. (2011). Opening doors: A strategy for social mobility. London: Breaking Barriers.

Cheshire, P. (2011). Are mixed community policies evidence based? A review of the research on neighbourhood effects. In M. van Ham, D. Manley, N. Bailey, L. Simpson, \& D. Maclennan (Eds.), Neighbourhood effects research: New perspectives. Dordrecht: Springer.

Clark, W. A. V., \& Dieleman, F. (1996). Households and housing: Choice and outcomes in the housing market. Rutgers: The State University of New Jersey.

Clark, W. A. V., \& Morrison, P. M. (2011). Residential sorting and social mobility: Evidence from the census and a large scale survey. Conference proceedings labor employment and work, Victoria University, Wellington, New Zealand.

Clark, W. A. V., \& Rivers, N. (2012). Community Choice in Large Cities: Selectivity and Ethnic Sorting Across Neighbourhoods. In M. van Ham, D. Manley, N. Bailey, L. Simpson, \& D. Maclennan (Eds.), Understanding neighbourhood dynamics: New insights for neighbourhood effects research. Dordrecht: Springer.

Cooke, T. J. (2008). Migration in a family way. Population, Space and Place, 14, 255-265.

Cooke, T. J. (2011). It is not Just the Economy: Declining migration and the rise of secular rootedness. Population, Space and Place, 17, 193-203.

Coulter, R., \& van Ham, M. (2013). Following people through time: An analysis of individual residential mobility biographies. Housing Studies OnlineFirst: doi:10.1080/02673037.2013.783903.

Dietz, R. D. (2002). The estimation of neighbourhood effects in the social sciences: An interdisciplinary approach. Social Science Research, 31, 539-575.

Dixon, S. (2003). Migration within Britain for job reasons. Labour Market Trends, 111, 191-201. 
Durlauf, S. N. (2004). Neighbourhood effects. In J. V. Henderson \& J. F. Thisse (Eds.), Handbook of regional and urban economics (pp. 2174-2242). Amsterdam: Elsevier.

Feijten, P. M., \& van Ham, M. (2009). Neighbourhood change... reason to leave? Urban Studies, 46, 2103-2122.

Friedman, S. (2011). Bringing Proximate Neighbours into the Study of US Residential Segregation. Urban Studies, 48, 611-639.

Friedrichs, J., Galster, G., \& Musterd, S. (2003). Neighbourhood effects on social opportunities: The European and American Research and policy context. Housing Studies, 18(6), 797-806.

Goldthorpe, J., \& Llewellyn, C. (1987). Social mobility and class structure in modern Britain. Oxford: Oxford University Press.

Hedman, L., van Ham, M., \& Manley, D. (2011). Neighbourhood choice and neighbourhood reproduction. Environment and Planning A, 43, 1381-1399.

Hulchanski, J. D. (2007). The three cities within Toronto: Income polarization among Toronto's neighbourhoods, 1970-2000. Centre for Urban and Community Studies Research Bulletin 41, University of Toronto.

Korpi, M., Clark, W. A. V., \& Malmberg, B. (2010). The urban hierarchy and domestic migration: The interaction of internal migration, disposable income and the cost of living, Sweden 1993-2002. Journal of Economic Geography Advance Access, 10(2), 1-27.

Manley, D. (2006). The modifiable areal unit phenomenon: An investigation into the scale effect using UK census data. PhD thesis, University of St Andrews.

Manley, D., van Ham, M., Bailey, N., Simpson, L., \& Maclennan, D. (Eds.). (2013). Neighbourhood effects or neighbourhood based problems? A policy context. Dordrecht: Springer.

Martin, J., \& Lichter, D. (1983). Geographic mobility and satisfaction with life and work. Social Science Quarterly, 64, 524-535.

Meen, G. (2006). Modelling local spatial poverty traps in England. International Centre for Housing and Urban Economics Discussion Paper. Reading: University of Reading.

Meen, G., Meen, J., \& Nygaard, C. (2007). A tale of two Victorian cities in the 21st century. International Centre for Housing and Urban Economics Discussion Paper 7, University of Reading.

Meen, G., Nygaard, C., \& Meen, J. (2012). The Causes of Long-Term Neighbourhood Change. In M. van Ham, D. Manley, N. Bailey, L. Simpson, \& D. Maclennan (Eds.), Understanding neighbourhood dynamics: New insights for neighbourhood effects research. Dordrecht: Springer.

Mulder, C. H., \& Hooimeijer, P. (1999). Residential relocations in the life course. In L. J. G. van Wissen \& P. A. Dykstra (Eds.), Population issues: An interdisciplinary focus. London: Plenum.

Noble, M., Wright, G., Dibben, C., Smith, G., McLennan, D., Anttila, C., et al. (2004). The English indices of deprivation 2004. London: ODPM.

Office for National Statistics (ONS). (2010). Comparing across countries' indices of deprivation: Guidance paper.

Quillian, L. (2003). How long are exposures to poor neighbourhoods? The long-term dynamics of entry and exit from poor neighbourhoods. Population Research and Policy Review, 22(3), 221-249.

Rabe, B., \& Taylor, M. (2010). Residential mobility, quality of neighbourhood and life course events. Journal of the Royal Statistical Society: Series A, 173, 531-555.

Robson, B., Lymperopoulou, K., \& Rae, A. (2008). People on the move: Exploring the functional roles of deprived neighbourhoods. Environment and Planning A, 40, 2693-2714.

Scottish Executive. (2004). Scottish index of multiple deprivation 2004: Summary technical report. Edinburgh: Scottish Executive.

South, S. J., \& Crowder, K. D. (1997). Escaping distressed neighbourhoods: Individual, community, and metropolitan influences. American Journal of Sociology, 102(4), 1040-1084.

South, S. J., Crowder, K., \& Chavez, E. (2005). Exiting and entering high-poverty neighbourhoods: Latinos, Blacks and Anglos compared. Social Forces, 84(2), 873-900.

Taylor, M., Brice, J., Buck, N., \& Prentice-Lane, E. (Eds.). (2010). British Household Panel Survey user manual volume A: Introduction, technical report and appendices. Colchester: University of Essex.

van Ham, M., \& Clark, W. A. V. (2009). Neighbourhood mobility in context: Household moves and changing neighbourhoods in the Netherlands. Environment and Planning A, 41, 1442-1459.

van Ham, M., \& Manley, D. (2010). The effect of neighbourhood housing tenure mix on labour market outcomes: A longitudinal investigation of neighbourhood effects. Journal of Economic Geography, 10, 257-282.

van Ham, M., Manley, D., Bailey, N., Simpson, L., \& Maclennan, D. (2012). New perspectives. In M. van Ham, D. Manley, N. Bailey, L. Simpson, \& D. Maclennan (Eds.), Neighbourhood effects research: New perspectives. Chapter 1 (pp. 1-22). Dordrecht: Springer.

Welsh Government. (2005). Welsh index of multiple deprivation 2005: Technical report. 
Wooldridge, J. M. (2010). Econometric analysis of cross section and panel data (2nd ed.). Cambridge (Massachusetts): MIT Press.

Worner, S. M., (2006). The effects of assortative mating on income inequality: A decomposition analysis. Centre for Economic Policy Research Discussion Paper 538, Canberra. 